\title{
Compression tests on a sandy silt at different suction and temperature levels.
}

\author{
B. François ${ }^{1}$, S. Salager ${ }^{2}$, M.S. El Youssoufi ${ }^{2}$, D. Ubals Picanyol ${ }^{1}$, L. Laloui ${ }^{1}$, C. Saix ${ }^{2}$ \\ ${ }^{1}$ Soil Mechanics Laboratory, Ecole Polytechnique Fédérale de Lausanne, Station 18, \\ CH-1015 Lausanne, Switzerland; Ph +41-21-6932315, Fax +41-21-6934153, email: \\ bertrand.francois@epfl.ch, david.ubalspicanyol@epfl.ch, lyesse.laloui@epfl.ch
}

${ }^{2}$ Mechanics and Civil Engineering Laboratory, Université Montpellier II, cc048, Place Eugène Bataillon, 34095 Montpellier cedex 5, France, email: salager@1mgc.univ-montp2.fr, elyous@1mgc.univ-montp2.fr, saix@1mgc.univ$\underline{\text { montp2.fr }}$

\begin{abstract}
This paper presents a unified thermo-mechanical experimental study on a remoulded unsaturated sandy silt and brings a contribution to the understanding of the fundamental mechanics of unsaturated soils in non-isothermal conditions. The experimental program was carried out at four temperatures and four suction levels using two thermo-hydro-mechanical (THM) cells, one isotropic and the other oedometric. The effect of suction and temperature on the compressibility and on the apparent preconsolidation pressure of the soil is addressed. Finally, an analytical expression of the evolution of the apparent preconsolidation pressure with respect to temperature and suction is proposed.
\end{abstract}

\section{Keywords}

Compression tests, Oedometric tests, isotropic tests, unsaturated soils, thermomechanics, preconsolidation pressure.

\section{Introduction}

Research interest in the thermo-mechanical behavior of unsaturated soils is growing as a result of an increasing number of geomechanical problems involving both thermal and capillary effects. In the field of environmental geomechanics, several relevant applications, such as feasibility studies of waste disposal, petroleum extraction or geothermal structures, require an accurate knowledge of the thermomechanical behavior of unsaturated soils. On the one hand, there exists a relatively large number of experimental studies concerning the mechanical behavior of unsaturated soil under isothermal conditions. On the other hand, a large number of experimental investigations concerning thermal effects on saturated soils have also 
been carried out. In contrast, experimental studies concerning the joint effect of capillarity and temperature on the mechanical behavior of soils are very limited.

This paper brings a contribution to the subject of the thermo-mechanical behavior of unsaturated soils under isotropic and oedometric conditions. In order to compress the experimental deadlines and, in addition, to compare our experimental and theoretical methods, this study was carried out as a collaboration between two groups: Université Montpellier II (France) and EPFL Lausanne (Switzerland). After presenting the material characteristics and the specifics of the cells used, the THM paths followed and the main results are presented. Finally, these results are interpreted in the light of a THM constitutive framework. In particular, the effect of suction and temperature on the compressibility indices and on the preconsolidation pressure of the soil is addressed.

\section{Material used}

The soil used in the research described here is a sandy silt (USCS classification: CLML) from the region of Sion (Switzerland). Its index properties are: $w_{L}=25.4 \%, I_{P}=$ $8.7 \%$. The clayey fraction represents $8 \%$, the silty one about $72 \%$ and the sandy one about $20 \%$. The sample preparation procedure consisted of mixing a known mass of dry soil with de-aired and demineralised water to an initial water content $w=1.5 w_{L}$. This water content value was assumed large enough to produce a saturated slurry. To remove any possible air bubbles trapped in the slurry, the soil was then vibrated. The initial void ratio $e_{0}$ at the slurry state varied between 0.7 and 9 (see Table 1).

Such a slurry can be used directly in the oedometric cell, but its consistence is not well adapted to the isotropic (triaxial) cell. Therefore, before performing the isotropic tests, a vertical consolidation pressure of up to $100 \mathrm{kPa}$ was applied to the sample in oedometric conditions. . A suction of $50 \mathrm{kPa}$ was then imposed. At the end of this preparation process, a mean void ratio e $=0.715$ (see Table 1) and a water content value $\mathrm{w}=23.3 \%$ were obtained.

\section{Experimental equipment}

THM oedometric cell. A new THM oedometric cell was developed in order to carry out the compression tests under controlled temperature and suction (Figure 1). The applied vertical pressure $\sigma_{v}$, the temperature $T$, the air pore pressure $u_{a}$ and the water pore pressure $u_{w}$ were controlled through four independent devices. The dimensions of the tested soil sample were $23 \mathrm{~mm}$ in height and $80 \mathrm{~mm}$ in diameter.

The suction (defined as the difference between the pore air and water pressures) within the sample was imposed using the axis translation technique (air overpressure method). The pore air pressure was applied uniformly by an air controller via a piston fixed to a perforated plate in contact with the top surface of the sample, while the pore water pressure was controlled beneath a 5 bar air-entry value ceramic disk at 
the bottom of the sample. The vertical pressure was applied by a water controller in a loading chamber surmounting the sample. These three controllers enabled the application and/or measurement of pressures and/or volume changes. The heating device consisted of a chamber surrounding the soil sample filled with circulating water that was heated to the required temperature. In order to reduce the laboratory temperature influence, the entire oedometer was placed in an insulated box. Finally, the vertical displacement was measured using a dial gauge fixed to the external frame and in contact with the air piston.

In order to maintain a constant temperature in the air and water controller chambers, a cooling chamber with a water bath at $22^{\circ} \mathrm{C}$ was added along the air and water circuits before reaching the controller cells. A constant back-pressure of $80 \mathrm{kPa}$ was maintained by the water controller to avoid pore water evaporation at high temperature. Moreover, a water reservoir was connected to the air pressure line to humidify the dried air before connecting it to the sample.

THM isotropic cell. In the same way, a THM isotropic cell was developed to follow isotropic loading paths under saturated and unsaturated conditions at different temperatures. The dimensions of the tested soil sample were $15 \mathrm{~mm}$ in height and 70 $\mathrm{mm}$ in diameter. Figure 2 shows a detailed description of the experimental setup. The suction was also applied by the air overpressure method. A pneumatic circuit enabled an air pressure to be imposed in the sample. In order to limit the phase changes in the sample, the air was first saturated with vapour. A pressure sensor was used to measure the water pressure in the hydraulic circuit, and also, due to continuity, the water pressure of the liquid phase in the sample. The difference between the air and water pressures yields the suction.

The isotropic mechanical stress was applied by pressurizing the air of the cylindrical cell. This induces a radial compression of the sample via the neoprene membrane, and a vertical one via the loading plate.

The solid parts of the THM isotropic cell were fitted with electrical resistances swallowed up in the mass. In order to reduce the influence of the laboratory temperature, the whole isotropic cell was placed in an insulated box. Two thermoelectric probes, set in the inferior and superior plates, were used to make sure that the settings were respected.

The method used to measure the water content variation consists in measuring the incoming and outgoing water volumes of the soil sample through the porous ceramic disk. The measurements were carried out using graduated burettes accurate to 0.05 $\mathrm{cm}^{3}$.

The measurement of vertical and radial displacements was made via two non-contact "Kaman" sensors. They measure, by magnetic field, the distance between each of them and their aluminium target stuck on the loading plate and on the sample under the neoprene membrane, respectively. 

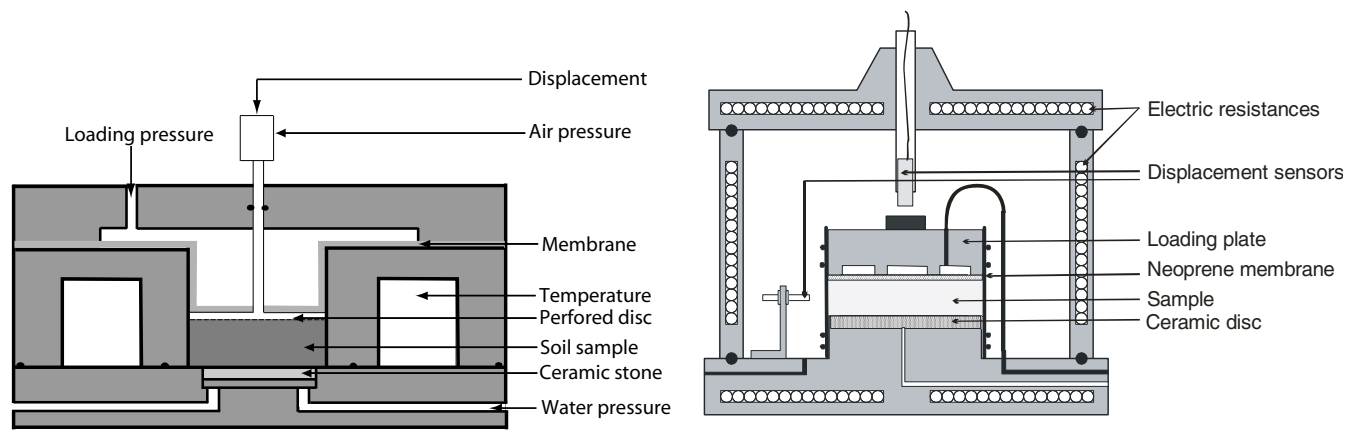

Figure 1: General scheme of the THM oedometric cell

\section{Figure 2 : General scheme of the THM isotropic cell}

\section{Constitutive framework}

The generalised Bishop's effective stress equation is very useful and efficient to describe the three phase nature of unsaturated soils continuously (Bishop, 1959 and Schrefler, 1984):

$$
\sigma_{i j}^{\prime}=\left(\sigma_{i j}-u_{a} \delta_{i j}\right)+S_{r}\left(u_{a}-u_{w}\right) \delta_{i j}
$$

where $\sigma_{i j}$ is the total external stress, $u_{a}$ and $u_{w}$ are the air and water pore pressures, respectively, $S_{r}$ is the degree of saturation and $\delta_{i j}$ is the Kroenecker's symbol. Equation 1 requires the hydric information, $S_{r}$, for the entire compression tests. The degree of saturation is related to the suction through the retention curve. It is shown that this $\left(S_{r}-s\right)$ curve depends on the temperature (Salager et al. 2006, Romero et al. 2001), on the dry density of the soils (Salager et al. 2007) and on the hydric paths followed (wetting or drying). In the present study, only drying paths were performed before compression, so the hydric hysteresis was not considered. Moreover, the retention curve was assumed to be independent of temperature and dry density.

The retention curve considered (Figure 3) was obtained at ambient temperature for an initial void ratio of 0.75 (Péron et al.,2007), which is quite close to the density encountered during the present compression tests. The suction corresponding to the air-entry value $s_{e}$ was around $50 \mathrm{kPa}$.

The choice of the generalised effective stress in order to interpret the experimental results may appear a bit complex with respect to the two classical independent stress variables (net stress and suction). Nevertheless, this is justified, in terms of constitutive modelling, by the convenience of using an unique stress variable coupled with the retention curve (Laloui and Nuth, 2005). 


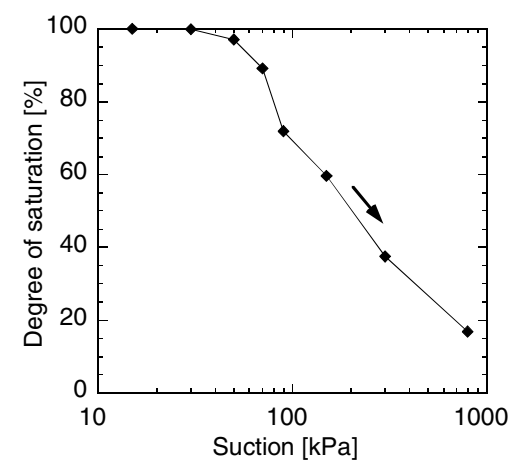

Figure 3: Water retention curve of Sion Silt

\section{Experimental paths and results}

As explained in the presentation of the experimental equipment, two experimental devices were used to carry out the set of THM experiments: a THM oedometer and an isotropic cell. This leads to two different mechanical stress paths: an oedometric path where the lateral strains are restrained and an isotropic path where the same stresses are controlled in the lateral and vertical directions.

In order to impose the THM initial conditions, before carrying out the mechanical compressions, the following steps were followed. For the oedometric tests, in order to define the initial preconsolidation pressure, a vertical stress of $100 \mathrm{kPa}$ was applied under saturated conditions. After an unloading to $10 \mathrm{kPa}$, the desired temperature and suction were then applied. For the isotropic tests, an initial suction of $50 \mathrm{kPa}$ was applied to facilitate the subsequent manipulation of the sample. Then, on this slightly unsaturated sample, an isotropic mechanical loading of $150 \mathrm{kPa}$ was applied, then followed by an unloading to $10 \mathrm{kPa}$ and the suction and the temperature imposition.

So, starting from a virgin remoulded and saturated slurry, these preliminary THM loadings enabled the desired THM state to be reached, in terms of temperature, suction and preconsolidation pressure. Nevertheless, the soil behavior during the preliminary steps was not considered and only the mechanical response during the final compression paths was studied. However, the thermal and hydric paths were carried out at a sufficiently overconsolidated state in order to ensure an elastic thermo-hydric response of the soil. In this way, the mechanically defined preconsolidation pressure was not modified during the temperature and suction imposition. Indeed, no thermal or hydric collapse was observed, which means that no yielding occurred during the temperature and the suction application.

A summary of the THM initial states before the final compression for all tests is presented in Table 1. The experimental results on the oedometric and isotropic mechanical paths are given in Figures 4 and 5, respectively. These results represent the variation of void ratio versus the generalised Bishop's effective stress. 
Table 1: Summary of the THM initial states before performing the compression paths

\begin{tabular}{lllllllll} 
Tests & $\begin{array}{l}\text { Mech. } \\
\text { path }\end{array}$ & $\begin{array}{l}\sigma_{c 0}^{\prime} \text { or } \\
p_{c 0}^{\prime}[\mathrm{kPa}]\end{array}$ & $\begin{array}{l}\left.{ }^{\circ} \mathrm{C}\right] \\
\end{array}$ & $\begin{array}{l}S \\
{[\mathrm{kPa}]}\end{array}$ & $\begin{array}{c}S_{r} \\
{[-]}\end{array}$ & $e_{0}[-]$ & $\sigma_{\text {net, }}$ or & $\sigma_{v}^{\prime}$ or \\
& & & & $p_{\text {net }}[\mathrm{kPa}]$ & $p^{\prime}[\mathrm{kPa}]$ \\
\hline LSSAT1(*) & Oedo & 250 & 22 & 0 & 1 & 0.79 & 1 & 1 \\
LSSAT3 & Oedo & 134 & 22 & 0 & 1 & 0.85 & 16 & 16 \\
LSSAT4 & Oedo & 100 & 80 & 0 & 1 & 0.90 & 11 & 11 \\
LSUNSAT1 & Oedo & 109 & 22 & 300 & 0.37 & 0.75 & 11 & 122 \\
LSUNSAT2 & Oedo & 109 & 80 & 300 & 0.37 & 0.73 & 11 & 122 \\
LSISO1 & Iso & 198 & 22 & 50 & 0.96 & 0.71 & 1 & 49 \\
LSISO2 & Iso & 198 & 45 & 50 & 0.96 & 0.68 & 50 & 98 \\
LSISO3 & Iso & 198 & 68 & 50 & 0.96 & 0.72 & 50 & 98 \\
LSISO4 & Iso & 198 & 68 & 300 & 0.37 & 0.66 & 60 & 171 \\
LSISO5 & Iso & 198 & 22 & 300 & 0.37 & 0.67 & 10 & 121 \\
\hline
\end{tabular}

(*) This test was carried out in a conventional oedometric cell

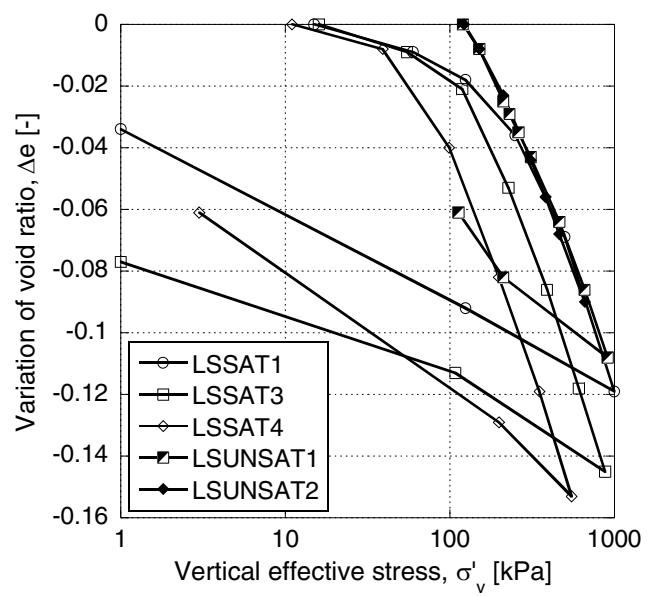

Figure 4: Oedometric compression tests: Variation of void ratio versus vertical effective stress

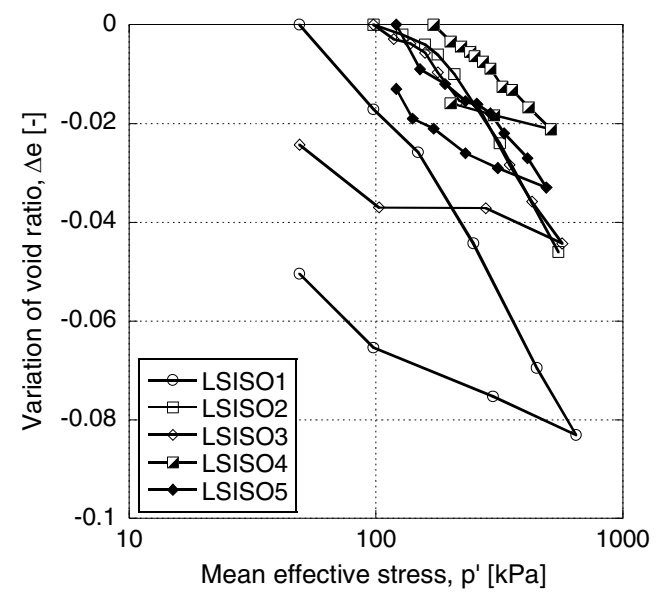

Figure 5: Isotropic compression tests: Variation of void ratio versus mean effective stress

\section{Interpretation}

The main objective of this experimental study was to understand the effect of temperature and suction on the evolution of the apparent preconsolidation pressure ( $\sigma_{v c}^{\prime}$ for the oedometric tests and $p_{c}^{\prime}$ for the isotropic ones) and of the compressibility indices (the expansion index, $\kappa^{\prime}$ and the compression one, $\lambda^{\prime}$ ). As these parameters are calculated in the generalised Bishop's effective stress reference (Eq. 1), they are written with an apostrophe.

For all the tests, the apparent preconsolidation pressure was determined using the empirical construction proposed by Casagrande (1936); the expansion index was 
calculated on the final unloading path by considering the slope between the first and the last point, while the three last points of the normal consolidation line were used to estimate the compression index. Table 2 gives the three measured parameters for all the THM compression tests performed.

Figures 6 and 7 present the compressibility indices with respect to temperature (Figure 6) and suction (Figure 7) values during the compression tests. The general trend of this set of results exhibits a very slight, almost negligible, effect of temperature and suction on the compressibility of the soils, at least for the range of temperature and suction considered in this experimental program. Only the compression index observed along isotropic mechanical paths seems to be affected by the suction level applied during compression. Indeed, $\lambda$ is almost divided in half for a suction change from 50 to $300 \mathrm{kPa}$.

Another important observation is that the compression index depends on the mechanical path followed. In fact, the compressibility observed on an oedometric path is clearly higher than that on an isotropic path for the same thermo-hydric conditions. This experimental evidence is not in accordance with the admitted similarity between isotropic and oedometric compressibilities for remoulded saturated clays (Biarez and Hicher, 1994). This may be due to the very low sample L/D ratio used in the isotropic cell. This configuration leads to an effect of the contact condition between the axial piston and the bottom of the sample. The friction which takes place at this level may reduce the deformation of the soil and so decreases the compression index. Therefore, it is difficult to compare the isotropic and oedometric compressibilities.

Table 2: The compression results in term of apparent preconsolidation pressure and compressibility indices

\begin{tabular}{lcccc} 
Test number & $\begin{array}{l}\text { Apparent } \\
\text { preconsolidation } \\
\text { pressure }\end{array}$ & $\begin{array}{l}\text { Normalised } \\
\text { preconsolidation } \\
\text { pressure }\end{array}$ & $\begin{array}{l}\text { Expansion } \\
\text { index }\end{array}$ & $\begin{array}{l}\text { Compression } \\
\text { index }\end{array}$ \\
\hline$\sigma_{c}^{\prime}$ or $p_{c}^{\prime}[\mathrm{kPa}]$ & $\sigma_{c}^{\prime} / \sigma_{c 0}^{\prime}$ or $p_{c}^{\prime} / p_{c 0}^{\prime}$ & $\kappa^{\prime}[-]$ & $\lambda^{\prime}[-]$ \\
\hline LSSAT1 & 250 & 1 & 0.012 & 0.060 \\
LSSAT3 & 134 & 1 & 0.010 & 0.072 \\
LSSAT4 & 77 & 0.77 & 0.018 & 0.070 \\
LSUNSAT1 & 185 & 1.7 & 0.023 & 0.065 \\
LSUNSAT2 & 164 & 1.5 & - & 0.061 \\
LSISO1 & 198 & 1 & 0.013 & 0.040 \\
LSISO2 & 184 & 0.92 & 0.009 & 0.037 \\
LSISO3 & 166 & 0.83 & 0.009 & 0.032 \\
LSISO4 & 264 & 1.33 & 0.006 & 0.022 \\
LSISO5 & 295 & 1.49 & 0.014 & 0.028 \\
\hline
\end{tabular}



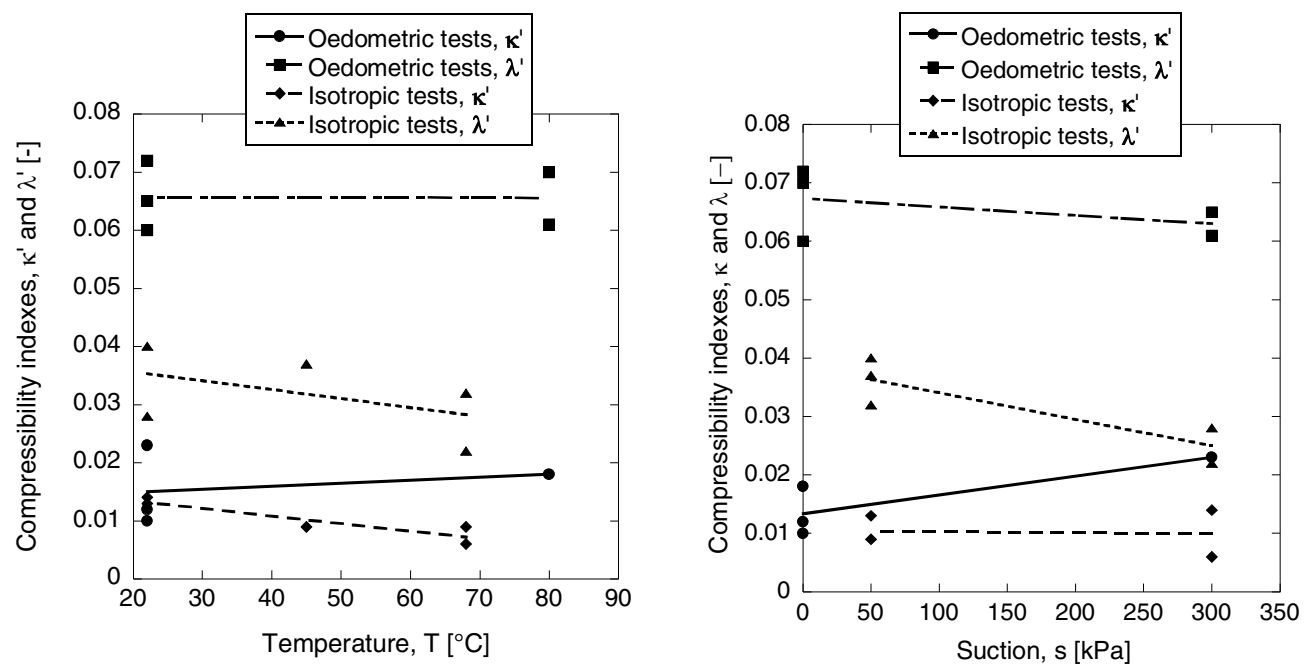

Figure 6: Evolution of the Figure 7: Evolution of the compressibility indices with compressibility indices with suction temperature

The yield limit characterised by the apparent preconsolidation pressure clearly depends on the thermal and hydric conditions of the soil. The yield surface tends to shrink when temperature increases, while it expands when suction increases. Figures 8 and 9 underline the effect of temperature and suction, respectively, on the apparent preconsolidation pressure. For the tested material, all the curves presented in Figures 8 and 9 appear to be parallel (at least for the same mechanical path). Therefore, the evolution of the apparent preconsolidation pressure with temperature seems to be unaffected by the hydric conditions and, inversely, the temperature does not influence the evolution of the yield limit with suction.

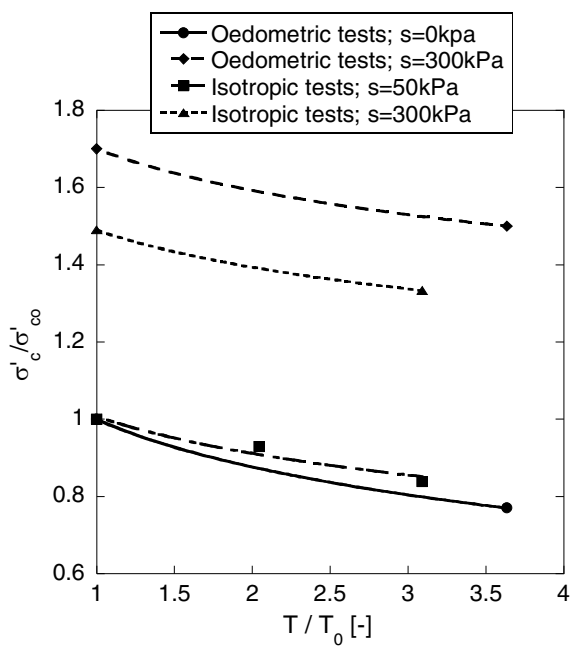

Figure 8: Evolution of the apparent Figure 9: Evolution of the apparent preconsolidation pressure temperature

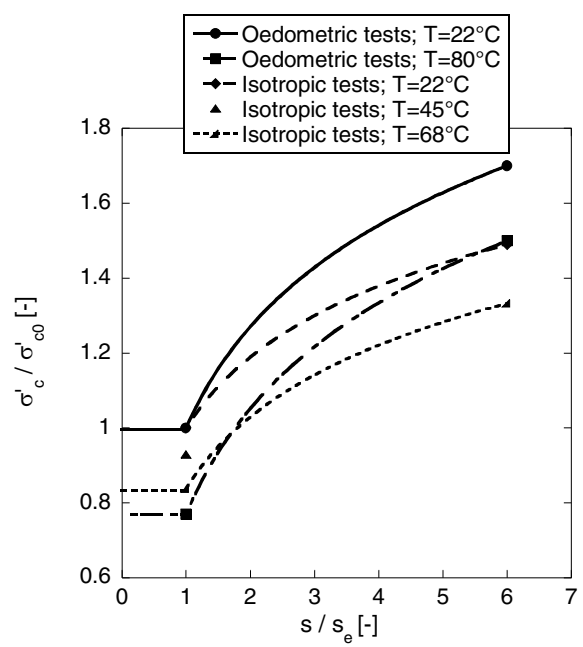

preconsolidation pressure with suction 
In the light of these experimental results, it is not easy to extract a quantitative expression for the apparent preconsolidation pressure with temperature and suction. Indeed, several additional results for intermediate temperature and suction values would be useful to complete and confirm the current trends. Nevertheless, with these first results, it seems that the logarithmic expression proposed by Laloui and Cekerevac (2003) for the evolution of the apparent preconsolidation pressure with temperature might be suitable, not only for the thermal evolution, but also for the hydric evolution of the yield limit, as shown in Figures 8 and 9. In this proposed expression, the preconsolidation pressure is supposed uninfluenced by suctions lower than the air-entry value, $s_{e}$ :

$$
\begin{cases}\sigma_{c 0}^{\prime}(s)=\sigma_{c 0}^{\prime}\left(T_{0}, s<s_{e}\right)\left\{1-\gamma_{T} \log \left\{\frac{T}{T_{0}}\right\}\right\}\left\{1+\gamma_{s} \log \left\{\frac{s}{s_{e}}\right\}\right\} & \text { if } s>s_{e} \\ \sigma_{c 0}^{\prime}(s)=\sigma_{c 0}^{\prime}\left(T_{0}, s<s_{e}\right)\left\{1-\gamma_{T} \log \left\{\frac{T}{T_{0}}\right\}\right\} & \text { if } s \leq s_{e}\end{cases}
$$

where $\gamma_{T}$ and $\gamma_{s}$ are the material parameters required to quantify the effect of temperature and suction on the apparent preconsolidation pressure, respectively. In the present case, $\gamma_{T}$ is independent of the THM conditions, while $\gamma_{s}$ seems to depend on the mechanical path. Indeed, the increase of the yield limit along the isotropic path seems smaller than that along the oedometric path.

\section{Conclusions}

A set of compression tests under different THM initial states were carried out on a sandy silt using an isotropic and an oedometric cell. The aim of this experimental program was to study the influence of combined temperature and suction on compressibility properties and on the apparent preconsolidation pressure. These results have been interpreted in the light of the generalised Bishop's effective stress equation. This tends to show that the compressibility indices are quasi-independent of temperature and suction. On the other hand, the apparent preconsolidation pressure is strongly influenced by temperature and suction. An increase in temperature tends to decrease the yield limit, while an increase in suction enhances this limit, at least for suctions higher than the suction of air entry value. Finally, a quantitative logarithmic expression requiring two material parameters (one for the thermal evolution and another for the hydric evolution) has been proposed to translate these qualitative observations.

\section{Acknowledgement}

This work was supported by the Swiss Academy of Engineering Sciences and the French Ministry of Foreign Affairs in the framework of an integrated action programme (PAI). The work of the Swiss group was partly funded by the Swiss State Secretariat for Education and Research SER, Grant OFES C04.0021. 


\section{References}

Biarez, J. and Hicher, P. (1994). Elementary Mechanics of soil Behaviour. Saturated remoulded soils, Rotterdam / Brookfield.

Bishop, A. W. (1959). The principle of effective stress. Tecnisk Ukeblad, 39, 859863.

Casagrande, A. (1936) The determination of the preconsolidation load and its practical significant. 1st Int. Conf. Soil Mech. Found. Eng., Cambridge, 6064.

Laloui, L. and Cekerevac, C. (2003). Thermo-plasticity of clays: An isotropic yield mechanism. Computer and geotechnics, 30, 649-660.

Laloui, L. and Nuth, M. (2005). An introduction to the constitutive modelling of unsaturated soils. Revue Européenne de Génie Civil, 9(5-6), 651-669.

Péron ,H., Hueckel,T., Laloui,L. (2007). An improved volume measurement for determining soil water retention curves. Geotechnical Testing Journal, 30(1), In Press

Romero, E., Gens, A., and Lloret, A. (2001). Temperature effects on the hydraulic behaviour of an unsaturated clay. Geotechnical and Geological Engineering, 19, 311-332.

Salager, S., El Youssoufi, M. S., Saix, C. (2007). Experimental study of the water retention curve as a function of void ratio. GeoDenver07.

Salager, S., Jamin, F., El Youssoufi, M. S., Saix, C. (2006). Influence de la température sur la courbe de rétention d'eau de milieux poreux. C. $R$. Mécanique 334, 393-398.

Schrefler B.A. (1984). The finite element method in soil consolidation (with applications to surface subsidence) - $\mathrm{Ph}$. D. Thesis, University College of Swansea, $\mathrm{C} / \mathrm{Ph} / 76 / 84$. 